\title{
Histoenzymatic studies on prenatal development of submandibular salivary gland in buffalo (Bubalus bubalis)
}

\author{
A. D. Singh and Opinder Singh
}

Department of Veterinary Anatomy, Guru Angad Dev Veterinary and Animal Sciences University, Ludhiana, Punjab, India. Corresponding author: Opinder Singh, e-mail: singhopinder68@gmail.com, ADS: dramandeep287@gmail.com Received: 20-08-2014, Revised: 04-11-2014, Accepted: 13-11-2014, Published online: 04-12-2014

doi: 10.14202/vetworld.2014.1032-1036. How to cite this article: Singh AD, Singh O (2014) Histoenzymatic studies on prenatal development of submandibular salivary gland in buffalo (Bubalus bubalis), Veterinary World 7(12): 1032-1036.

\begin{abstract}
Aim: The present study was aimed at elucidating the distribution of various enzymes in the submandibular salivary gland of buffalo during prenatal development and correlation of these enzyme systems with the secretory activity of the gland.

Materials and Methods: The study was carried out on submandibular salivary gland of 15 buffalo fetuses ranging from $11 \mathrm{~cm}$ curved crown-rump length (CVRL) (78 days) to $100 \mathrm{~cm}$ CVRL (full term). The fetuses were categorized into three groups based on their CVRL.

Results: A weak activity of phosphatases and oxidoreductases was observed in the acinar cells and ductular epithelium at 11-19 cm CVRL (78-114 days). From 28 to 37 cm CVRL (136-157 days), a weak to moderate diffused granular alkaline phosphatase (AKPase) activity was observed in the seromucous acini whereas oxidoreductases showed moderate activity. The enzyme activity showed progressively increased with the advancement of the gestation period. The AKPase activity was more in the lumen of acini and along the intercellular canaliculi at 42-100 cm of CVRL (168 days - full term). Large ducts exhibited strong activity for oxidoreductases indicating increased metabolic activity of the cells.
\end{abstract}

Conclusion: The fetuses of Group I showed a uniform weak activity in the acinar cells and ductular epithelium of the gland. In Group II, the enzymes showed a weak to moderate activity which progressively increased with the advancement of gestation period. The enzymes related to Group III showed a strong positive activity for enzymes which reflected higher secretory activity of the gland.

Key words: buffalo, enzyme histochemistry, prenatal, submandibular salivary gland.

\section{Introduction}

The submandibular salivary gland being one of the major salivary glands contributes to a substantial amount of saliva secreted into the mouth. Saliva contains water, various enzymes, mucopolysaccharides, and lubricating glycoproteins. The gland has an important role to provide lubrication for eating and vocalization, aid digestion, and the supply saliva for $\mathrm{pH}$ buffering [1]. In general, the major salivary glands of the herbivores are better developed than those of the carnivores. The salivary glands may be classified on the basis of their secretions as serous, mucous, or seromucous (mixed) glands. The distribution of these types varies from species to species [2]. Saliva is secreted into the oral cavity via a series of ducts in the ductal system. Dysfunction of salivary secretion (hyposalivation) causes xerostomia (dry mouth) and sequentially leads to severe dental caries as well as oral mucosal disorders [3]. The salivary glands also secrete IgA, potassium and sodium [4].

Enzyme histochemistry serves as a link between biochemistry and morphology. It can be used to locate many enzymes, including phosphatases,

Copyright: The authors. This article is an open access article licensed under the terms of the Creative Commons Attributin License (http:// creative commons.org/licenses/by/2.0) which permits unrestricted use, distribution and reproduction in any medium, provided the work is properly cited. dehydrogenases, and esterases. Alkaline phosphatase (AKPase) is associated with the ionic exchange across the membrane. It is found abundantly in endothelium of smaller blood vessels and also occurs in the cells specialized for endocytosis and pinocytosis. Glucose-6-Phosphatase (G-6-Pase) is related to carbohydrate metabolism. Succinic dehydrogenase (SDH) is found in all aerobic cells, and so is an essential part of Kreb’s cycle. Diaphorases activities are indicative of mitochondrial activity as well as cytoplasmic electron transport. These enzymes also serve as biochemical markers for tissue damage. The purpose of this study was to accurate localization of these enzymes in the submandibular salivary gland of buffalo during prenatal life and thereby correlated with physiological functions of tissues or organs. The literature on histoenzymatic studies of buffalo submandibular salivary gland during prenatal life was scanty.

The present study was, therefore, undertaken with the aim to observe the distribution of various enzymes in the submandibular salivary gland of buffalo during prenatal development.

\section{Materials and Methods}

\section{Ethical approval}

This study was conducted after approval by the research committee and Institutional animal ethics committee. 


\section{Samples}

The present study was conducted on the 15 buffalo fetuses ranging from $11 \mathrm{~cm}$ curved crown-rump length (CVRL) to $100 \mathrm{~cm}$ CVRL (78 days to full term). The approximate age of the fetus in bovines was estimated using the formula [5].

$\mathrm{Y}=28.66+4.496 \mathrm{X}(\mathrm{CVRL}<20 \mathrm{~cm})$

$\mathrm{Y}=73.544+2.256 \mathrm{X}(\mathrm{CVRL} \geq 20 \mathrm{~cm})$

Where $\mathrm{Y}$ is age in days, and $\mathrm{X}$ is CVRL in $\mathrm{cm}$.

The fetuses were divided into three groups, five in each group, based on their CVRL viz; Group I (CVRL between 0-20 cm, 0-118 days), Group II (CVRL > 20-40 cm, 119-163 days) and Group III (CVRL > $40 \mathrm{~cm}, 164$ days - full term). The buffalo fetuses were collected from the abattoir. Fresh unfixed tissues from the submandibular salivary gland of buffalo fetuses were collected in liquid nitrogen.

\section{Cryostat sectioning}

Cryostat sections of $10 \mu \mathrm{m}$ thickness at $-20^{\circ} \mathrm{C}$ were obtained on glass slides and incubated with different substrates to study the distribution pattern of different enzymes viz; phosphatases: AKPase and G-6-Pase, non-specific esterase (NSE) and oxidoreductases; monoamine oxidase (MAO), SDH, glutamic dehydrogenase (GLD), lactic dehydrogenase (LDH), G-6-Pase dehydrogenase (G-6-PD), nicotinamide adenine dinucleotide diaphorase (NADH-d), and Nicotinamide adenine dinucleotide phosphate diaphorase (NADPH-d) as described in Table-1 [6].

\section{Results and Discussion}

\section{Group I}

At $11 \mathrm{~cm}$ CVRL (78 days), a uniform weak AKPase activity was observed in the acinar cells. The activity of G-6-Pase was weak, granular, and more basal in acini at $16 \mathrm{~cm}$ CVRL (100 days). At the same stage of gestation, NSE showed very weak activity in acinar cells as well as in ductular epithelium. At $19 \mathrm{~cm}$ CVRL (114 days), a weak activity of SDH,
G-6-PD, NADH-d, NADPH-d, LDH, GLD, MAO was observed in acinar cells indicating weak physiological activity in Group I.

\section{Group II}

At $28 \mathrm{~cm}$ CVRL (136 days), a weak to moderate diffused granular AKPase activity was observed in acinar epithelium and blood vessels. The ductular epithelium also showed a weak to moderate positive activity for AKPase. The enzyme activity in the ductular epithelium increased with the advancement of age. Similar results were also reported in adult buffalo [7], and in goat submandibular salivary gland [8]. GLD showed moderate activity in the basal portions of the serous acinar cells than mucous acinar cells and ductular epithelium at same stage of gestation (Figure-1).

At $30 \mathrm{~cm}$ CVRL (141 days), the AKPase showed granular and apical localization in the ductular cells. Some authors reported the fine granular strong AKPase activity in the acinar cells of mandibular salivary gland of sheep. Myoepithelial cells were also strongly positive. Intense NSE activity was localized in the nerve fibers of intralobular and interlobular connective tissues. SDH activity was fine, granular, and evenly distributed in acinar cells [9]. A weak to moderate G-6-Pase activity was seen close to the basement membrane and a weak NSE activity was seen in close vicinity of the large ducts. At $32 \mathrm{~cm}$ CVRL (145 days), NADPH-d showed a moderate activity in serous acini and interlobular ducts (ILDs) (Figure-2). However, MAO showed a weak granular perinuclear activity at same CVRL. Different authors observed that the submandibular salivary glands of the Arabian camel (Camelus dromedarius) had a considerable activity of AKPase, SDH, and NSE, but weak activity of MAO [10]. At 37 cm CVRL (157 days), a moderate activity of SDH, LDH, GLD, G-6-PD, NADH-d, and NADPH-d was observed in the seromucous acini and in large ducts (Figure-3). Similar findings were

Table-1: Histoenzymatic methods used on cryostat sections of submandibular salivary glands of buffalo fetuses.

\begin{tabular}{|c|c|c|c|c|}
\hline Enzyme & Substrate & Method & Reference & I ncubation time \\
\hline \multicolumn{5}{|c|}{ Phosphatases } \\
\hline AKPase & $\begin{array}{l}\text { Naphthol ASMX phosphate disodium } \\
\text { salt in combination with fast blue RR }\end{array}$ & $\begin{array}{l}\text { Coupling azo dye } \\
\text { method }\end{array}$ & [6] & $30 \min$ \\
\hline G-6-Pase & G-6-Pase and lead nitrate & Lead nitrate method & [6] & $20 \mathrm{~min}$ \\
\hline \multicolumn{5}{|c|}{ Oxidoreductases } \\
\hline $\mathrm{SDH}$ & Di-Na succinate & Nitro BT method & [6] & $30 \mathrm{~min}$ \\
\hline LDH & Na-DL lactate & Nitro BT method & [6] & $30 \mathrm{~min}$ \\
\hline GLD & Na-L glutamate & Nitro BT method & [6] & $30 \mathrm{~min}$ \\
\hline G-6-PD & Di-Na glucose-6-phosphate & Nitro BT method & [6] & $30 \mathrm{~min}$ \\
\hline MAO & Tryptamine and adrenaline & Nitro BT method & [6] & $60 \mathrm{~min}$ \\
\hline $\mathrm{NADPH}-\mathrm{d}$ & Co-enzyme NADPH & Nitro BT method & [6] & $30 \mathrm{~min}$ \\
\hline $\mathrm{NADH}-\mathrm{d}$ & Co-enzyme NADH & Nitro BT method & [6] & $30 \mathrm{~min}$ \\
\hline \multicolumn{5}{|l|}{ Esterases } \\
\hline NSE & Naphthol acetate & $\begin{array}{l}\text { Naphthol acetate } \\
\text { method }\end{array}$ & {$[6]$} & $15 \mathrm{~min}$ \\
\hline
\end{tabular}

AKPase=Alkaline phosphatase, G-6-Pase=Glucose- 6 phosphatase, SDH=Succinic dehydrogenase, LDH=Lactic dehydrogenase, GLD=Glutamic dehydrogenase, G-6-PD=Glucose-6-phosphate dehydrogenase, MAO=Monoamine oxidase, $\mathrm{NADPH}-\mathrm{d}=\mathrm{Nicotinamide}$ adenine dinucleotide phosphate diaphorase, NADH- $d=\mathrm{Nicotinamide}$ adenine dinucleotide diaphorase, NSE $=$ Non-specific esterase 


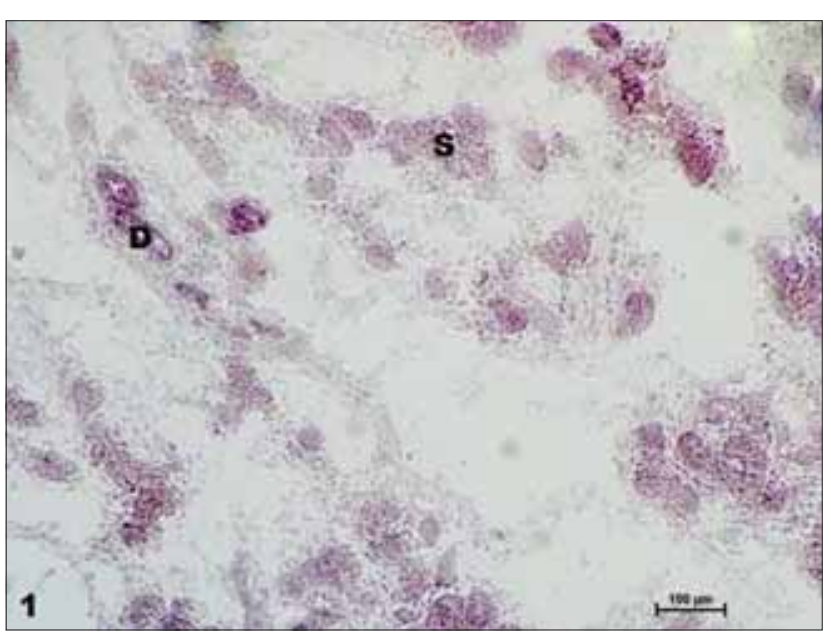

Figure-1: Photomicrograph showing weak to moderate glutamic dehydrogenase activity in serous acinar cells (S) and duct (D) of submandibular salivary gland of buffalo fetus at $28 \mathrm{~cm}$ curved crown-rump length (136 days) (Nitro BT method $\times 100$ ).

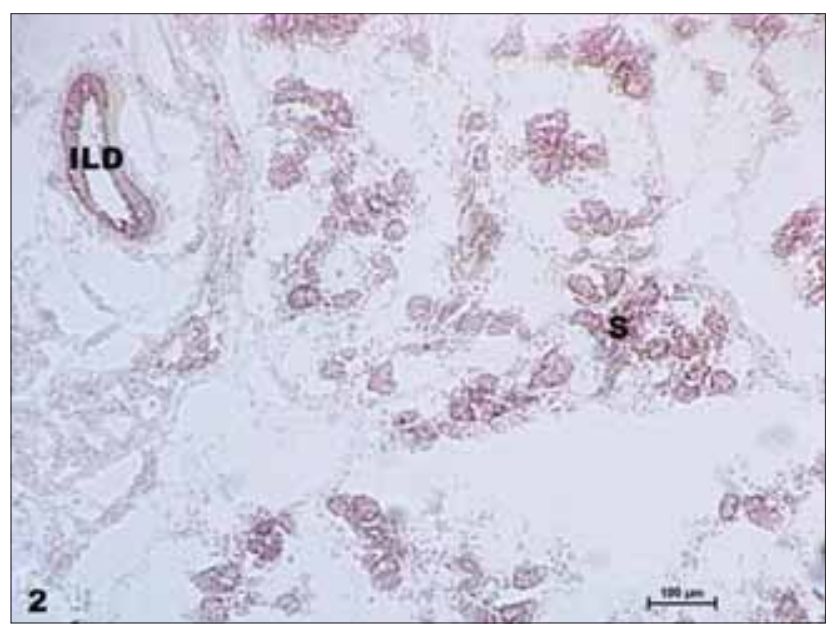

Figure-2: Photomicrograph at the age of $32 \mathrm{~cm}$ curved crown-rump length (145 days) showing moderate nicotinamide adenine dinucleotide phosphate diaphorase activity in serous acini (S) and interlobular duct of submandibular salivary gland of buffalo fetus (Nitro BT method $\times 100$ ).

observed in mandibular salivary gland of pig during prenatal life [11].

\section{Group III}

At 42 cm CVRL (168 days), AKPase activity was more in the basal portions of the acini, which reflected greater metabolic activity towards the basement membrane (Figure-4). The larger ducts presented enzyme activity for AKPase, NSE, MAO, and SDH. This is in accordance with the findings of the some authors in guinea pig [12], in goat [8] and in adult buffalo [7]. G-6-Pase activity was moderate and perinuclear. NSE showed low to moderate granular localization in the ductular cells. At 54 cm CVRL (195 days), AKPase positive granules were concentrated in the luminal parts of acinar cells and along the intercellular canaliculi. A moderate to strong activity of NADH-d was observed in acinar cells and in ductular epithelium at same stage of gestation (Figure-5). Oxidoreductases

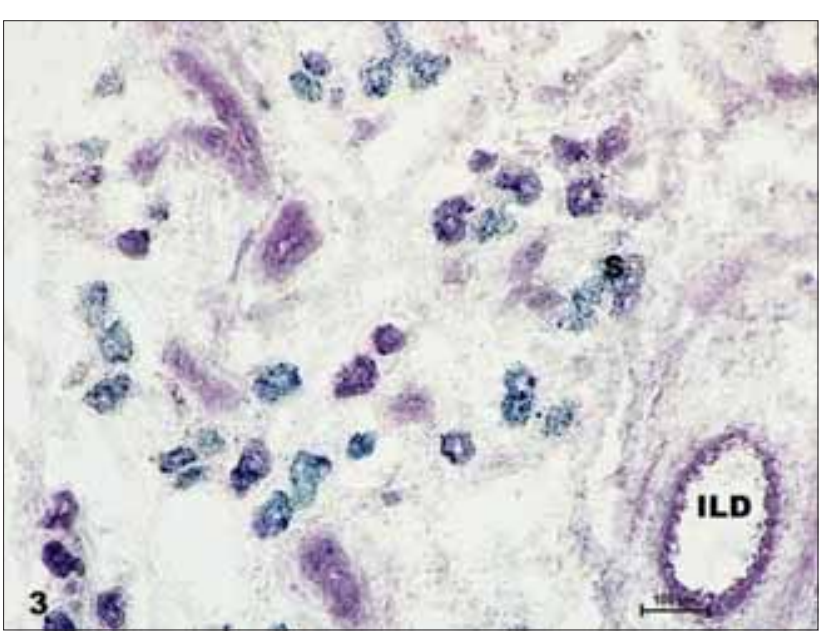

Figure-3: Photomicrograph of $37 \mathrm{~cm}$ curved crown-rump length ( 157 days) buffalo fetus showing moderate glucose6-phosphate dehydrogenase activity in serous acinar cells (S) of submandibular salivary gland. Interlobular ductular epithelium also showed similar type of activity (Nitro BT method $\times 100)$.

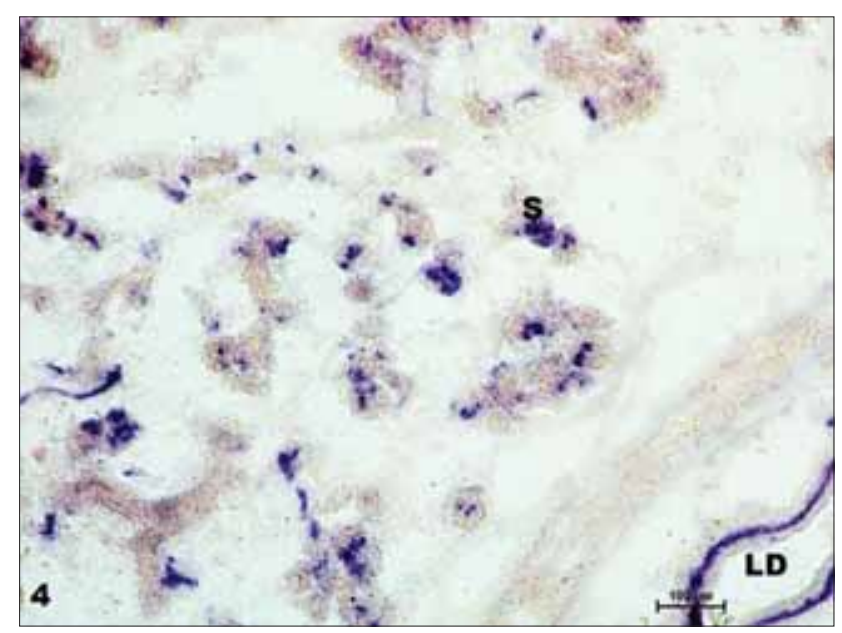

Figure-4: Photomicrograph showing moderate granular alkaline phosphatase activity in serous acini (S) and large duct (D) of submandibular salivary gland of buffalo fetus at $42 \mathrm{~cm}$ curved crown-rump length (168 days) (Coupling azo dye method $\times 100)$.

were strongly demonstrated in the acinar and in ductular cells with higher concentrations in the striated and ILDs. This group of enzymes was considered more physiologically active components of the submandibular salivary gland. Similar findings were noticed in adult buffalo [7] and in submandibular salivary gland of goat [8].

At $75 \mathrm{~cm}$ CVRL (242 days), AKPase showed positive perinuclear activity in acinar cells and the ducts were positive. The AKPase was related to ionic movement across the membrane [13]. AKPase activity was reported in the seromucous acini and in ducts of the submandibular salivary gland of adult buffalo [7]. G-6-Pase showed a moderate positive activity in the acinar cells and in ductular epithelium. In the ducts, it was more basally. A higher activity of these phosphatases reflected higher secretory activity in submandibular salivary gland. SDH activity was strong, granular 
and evenly distributed in acinar cells, at same stage of gestation (Figure-6). Many authors described the same in case of prenatal pig [14]. At $100 \mathrm{~cm}$ CVRL (full term), the AKPase was confined to the myoepithelial cells and blood capillaries. The periductal nerve plexus had strong AKPase activities. Activity of oxidoreductases was moderate in the mucous acini of submandibular salivary gland while the serous acini and demilunes were intensely positive. These results were reported in submandibular salivary gland of adult buffalo [7]. The localization pattern of these oxidoreductases in the fetal submandibular salivary gland reflected higher physiological activity in the acinar cells than in the ductular epithelium. The intercalated duct showed strong enzyme activity for AKPase, NSE, MAO, and SDH. The distribution of LDH and MAO was almost identical to that of SDH. However, the LDH activity was slightly strong. It was intense in the striated ducts and strong in large ducts. NADPH-d activity was strong in ductular epithelium. Similar

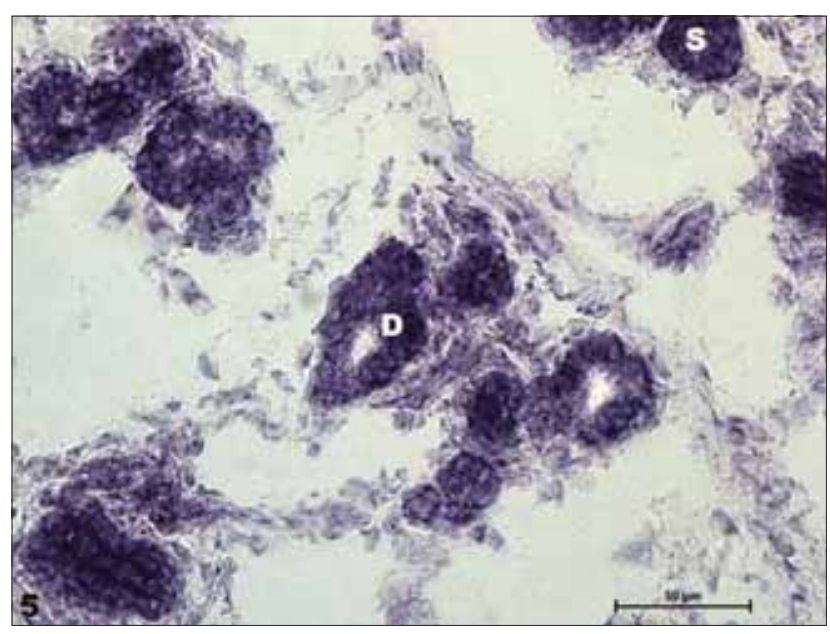

Figure-5: Photomicrograph of $54 \mathrm{~cm}$ curved crownrump length (195 days) buffalo fetus showing moderate to strong nicotinamide adenine dinucleotide diaphorase activity in serous acini (S) and ductular epithelium (D) of submandibular salivary gland (Nitro BT method $\times 400$ ).

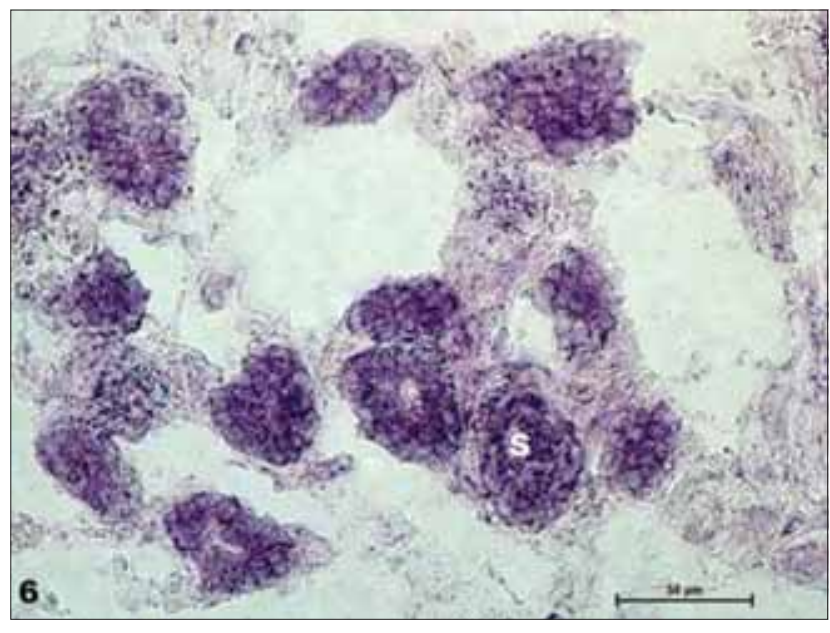

Figure-6: Photomicrograph showing strong granular succinic dehydrogenase activity in serous acinar cells (S) of submandibular salivary gland of buffalo fetus at $75 \mathrm{~cm}$ curved crown-rump length (242 days) (Nitro BT method $\times 400$ ). findings were observed in sheep [15]. The high basal activities of SDH, LDH and NADPH-d were due to basal mitochondria and were associated with high energy production to meet the energy requirement for active and rapid transport of ions and water.

\section{Conclusion}

The present study suggests that the enzymes related to Group I showed a uniform weak activity in the acinar cells and ductular epithelium of the gland. In Group II, the enzymes showed a weak to moderate activity which progressively increased with the advancement of gestation period. The fetuses of Group III showed a strong positive activity for enzymes which reflected higher secretory activity of the gland.

\section{Authors' Contributions}

ADS has planned and designed the study. OS analyzed the data and provided technical support. ADS prepared the manuscript under the guidance of OS. Both authors read and approved the final manuscript.

\section{Acknowledgments}

The authors are thankful to Guru Angad Dev Veterinary and Animal Sciences University (GADVASU), Ludhiana for providing all type of facilities to carry out the study. The funding for this study was provided by College of Veterinary Sciences, GADVASU, Ludhiana.

\section{Competing I nterests}

The authors declare that they have no competing interests.

\section{References}

1. Moghaddam, Y.F., Darvish, J., Mahdavi, S.N., Abdulamir, A.S., Mousavi, M. and Daud, S.K. (2009) Comparative histological and histochemical inter-species investigation of mammalian submandibular salivary glands. Res. J. Appl. Sci., 4: 50-56.

2. Konig, H.E. and Liebich, H.G. (2004) Veterinary Anatomy of Domestic Animals: Textbook and Colour Atlas. $1^{\text {st }}$ ed. Stuttgart, Germany, Schattauer Co. p284-286.

3. Featherstone, J.D. (2000) The science and practice of caries prevention. J. Am. Dent. Assoc., 131: 887-9.

4. Aspinall, V. and Reilly, M.O. (2004) Introduction to Veterinary Anatomy and Physiology. An Imprint of Elsevier Ltd., London. p110-111.

5. Soliman, M.K. (1975) Studies on the physiological chemistry of the allantoic and amniotic fluids of buffalo at various periods of pregnancy. Indian Vet. J., 52: 106-111.

6. Chayen, J., Butcher, R.G., Bitensky, L. and Poulter, L.W. (1969) A Guide to Practical Histochemistry. Lippincott, Philadelphia. p105-150.

7. Venkatakrishnan, A. (1994) Ph.D. Thesis on "Morphogenesis, Histomorphology and Histochemistry of the Mandibular Salivary Gland of the Buffalo" Submitted to Tamilnadu Veterinary and Animal Sciences University.

8. Kishore, P.V.S., Sundararao, K.V. and Gopinath, S. (1998) Histological and histochemical studies on the mandibular salivary gland of goat (Capra hircus). Indian J. Vet. Anat., 10: 88-9.

9. Roy, K.S. and Pawar, H.S. (1989) Histochemical and histoenzymological study on mandibular salivary gland of 
sheep. Indian J. Anim. Sci., 59: 810-812.

10. Asgah, N.A., Jarrar, B.M. and Taib, N.T. (1990) Structure and histochemistry of the sublingual salivary glands of the one-humped camel (Camelus dromedarius). Rev. Elev. Med. Vet. Pays Trop., 43: 519-527.

11. Pospieszny, N., Kuryszko, J., Juszczyk, M. and Adamski, M. (2010) Morphological and histological analysis of the mandibular gland and sublingual glands in prenatal period of the pig. Bull. Vet. Inst. Pulawy, 54: 351-355.

12. Heap, P.F. and Bhoola, K.D. (1970) Ultrastructure of granules in the submaxillary gland of the guinea pig. J. Anat., 107: 115-130.
13. Cope, G.H. (1977) Stereological analysis of the mitochondrial compartment of the rabbit parotid gland before and after isoprenaline-induced degranulation. J. Anat., 124: 323-333.

14. Zhou, J., Wang, H., Yang, G., Wang, X., Sun, Y., Song, T., Zhang, C. and Wang, S. (2010) Histological and ultrastructural characterization of developing miniature pig salivary glands. Anat. Rec., 293: 1227-1239.

15. Muthukrishnan, S. (2011) Ph.D. Thesis on "Microanatomical Studies on the Parotid and Mandibular Salivary glands in Sheep (Ovis aries)" Submitted to Tamilnadu Veterinary and Animal Sciences University.

$* * * * * * * *$ 